\title{
LA IGLESIA VISIGODA DE MORÓN DE LA FRONTERA (SEVILLA)
}

\section{THE VISIGOTHIC CHURCH OF MORÓN DE LA FRONTERA (SEVILLA)}

\author{
por
}

\author{
MANUEL VERA REINA
}

\begin{abstract}
RESUMEN La iglesia visigoda de Morón de la Frontera (Sevilla) constituye un hallazgo de gran interés para el conocimiento del proceso de cristianización de la comarca sur de la provincia de Sevilla. A lo largo de las siguientes páginas abordaremos el estudio e interpretación de los restos arquitectónicos de la basílica y de los principales materiales recuperados durante su excavación.
\end{abstract}

\begin{abstract}
The discovery of a visigothic church in Moron de la Frontera (Seville) has been of great interest for the knowledge of the Christianization process in the south district of the county of Seville. Along the following pages we will tackle the study and interpretation of the architectural remains of the basilica and the main materials recovered during the excavation.
\end{abstract}

Morón de la Frontera se encuentra $63 \mathrm{Km}$ al sudeste de la ciudad de Sevilla (fig. 1). Su asentamiento histórico se levanta en un cerro de $296 \mathrm{~m}$. de altura máxima, emplazado entre los $371^{\circ} 07^{\prime} 16^{\prime \prime}$ de latitud norte y los $51^{\circ} 26^{\prime} 50^{\prime \prime}$ de longitud oeste. Esta ubicación viene determinada por su posición de bastión comunicativo y puerta de entrada entre la Campiña-Valle del Guadalquivir y la Serranía de Cádiz y Ronda. Morón destaca, por tanto, por ser una zona de contacto entre dos medios físicos y humanos diferentes: el del pie de monte de la Sierra Sur sevillana y el de las ricas llanuras que se extienden desde el norte y oeste del pueblo hasta el río de Guadalquivir.

El lugar exacto de la excavación se conocía como la Huerta de San Miguel y se halla situado al sudeste del pueblo, a los pies de la ladera nororiental del cerro del Castillo (30STG825118) a unos cien metros de la torre albarrana de la fortaleza y a unos cuarenta metros de la fachada de la epístola de iglesia de San Miguel (fig. 1).

La intervención arqueológica estuvo motivada por la puesta en marcha del proyecto de reordenación de las zonas aledañas al castillo; el cual preveía una intervención de gran envergadura en las laderas del cerro. La excavación se llevó a cabo entre los meses de julio-septiembre de 1990 y fue dirigida por R. Fernández Ruiz. 
La planta general del yacimiento se asemejaba a un rectángulo seccionado en su ángulo nordeste. Englobaba una superficie total de $1417 \mathrm{~m}^{2}$ dividida en tres plataformas que situadas a diferentes alturas configuraban un plano ascendente en dirección norte-sur. El relleno arqueológico, lógicamente, mostraba una notable diferencia de una bancada a otra. Así en la media y superior, que son las que nos interesan, la secuencia estratigráfica alcanzaba los $-2,50 \mathrm{~m}$. desde la rasante del terreno.

En la bancada media se apreciaba una concentración mayor de grandes sillares sin disposición aparente por lo que se determinó abrir un sondeo de amplias dimensiones en el que pudo recuperarse, además de una interesante secuencia ocupacional que iba desde época tardorromana hasta finales del siglo pasado, los vestigios pésimamente conservados de una basílica visigoda. Esta iglesia fue seriamente seccionada por las tareas de remodelación que se llevaron a cabo en los años sesenta en todo el espacio circundante a la iglesia de San Miguel.

El objeto de este artículo es precisamente el estudio monográfico de los restos arquitectónicos pertenecientes a dicha iglesia. No obstante, hay que señalar que a lo largo del trabajo incluiremos un apartado dedicado a una serie de hallazgos, de distinta naturaleza y funcionalidad, que fueron recuperados en el transcurso de la excavación o bien en las proximidades inmediatas del edificio en paquetes descontextualizados. También introduciremos aquí el examen de ciertos materiales que a través de la documentación histórica sabemos que aparecieron en el lugar donde se encuentra la basílica. Con todo ello obtendremos un volumen mayor de datos que nos permitirá ofrecer una lectura más completa y rigurosa acerca de la conformación primitiva del edificio.

Los escasos restos conservados de la basílica suponen, por el momento, los únicos vestigios constructivos de cierta entidad adscribibles en la ciudad de Morón al período visigodo. Constituyen, por tanto, una información de primer orden para explicar importantes problemas relacionados con el asentamiento tardorromano de la ciudad así como del período de transición al mundo musulmán.

\section{ACTUACIONES EN LA BASÍLIĊA.}

Antes de avanzar en la descripción y análisis de la construcción conviene detenerse brevemente en el examen de la documentación escrita existente sobre la basílica. Las primeras y quizás las más valiosas informaciones al respecto se las debemos a A. Bohorques quien comenta al describir el perímetro de la cerca del castillo "... donde había una puerta llamada la Barrera de San Micas, porque salía a la ermita de este nombre; de alli al patio de la parroquia de San Miguel, que era la ermita de San Micas, donde por el año de mil y seiscientos y diecinueve se descubrieron los cimientos..." (Bohorques 1994: 24). No hay duda que se refiere a la misma iglesia que nosotros hemos excavado. Desgraciadamente, nada nos dice en esta escueta noticia del estado de conservación, qué zonas exactamente fueron descubiertas, etc.

El siguiente suceso que afectaría plenamente al yacimiento se produce en los albores del siglo XIX cuando una epidemia de fiebre amarilla obligó a habilitar nuevos lugares de enterramiento ya que los cementerios tradicionales quedaron rápidamente desbordados a causa de la elevada tasa de mortalidad que azotaba al pueblo. Una de las zonas habilitadas al respecto fue el patio de la parroquia de San Miguel (Collantes de Terán y Caamaño 1990: 193-197). No sabemos de qué modo pudo afectar a los restos arqueológicos allí existentes el uso funerario que se le dio a toda aquella área aunque, por el comportamiento observado en sitios próximos, debió de tratarse de una afección muy puntual.

El empleo de estas dependencias como campo santo manifiesta claramente el descuido que en aquellas fechas padecían las zonas anexas a la iglesia. Pues bien, este proceso de abandono concluye en 1812 cuando las tropas francesas en retirada destruyen el archivo de la parroquia (García 1982: 188-191). Todo el sector meridional de la iglesia quedó como un páramo desierto que pronto comenzó a utilizarse como huerta, uso que ha mantenido hasta prácticamente nuestros días. 
Por último, en el presente siglo este espacio no sufre transformaciones importantes hasta la década de los sesenta cuando, junto a la renovación de la actual parroquia de San Miguel, se reforma el caserío colindante. Ello supuso la destrucción de buena parte de este sector urbano y de más de dós tercio de la iglesia visigoda.

\section{DESCRIPCIÓN DEL EDIFICIO.}

Los restos conservados de la primitiva basílica ocupan en la actualidad la plataforma media de la plazuela meridional de S. Miguel. Toda la edificación muestra una potente fábrica bastante unitaria en apariencia que alcanza algo más del metro de altura. Son muy escasos los elementos o disposiciones asociados a la construcción que han permanecido. No obstante, esta carencia queda de algún modo paliada por la interesante relación de piezas que pudieron recuperarse en los desmontes de las bancadas próximas aunque la mayor parte de estos materiales planteen interrogantes insalvables acerca de su situación o función original.

Los vestigios de la basílica corresponden a la mitad meridional de una cabecera tripartita por lo que pueden diferenciarse desde un punto de vista formal dos estancias unidas por un grueso muro medianero (fig. 2).

La habitación meridional, única que se conserva íntegra, constituye una sala rectangular de 2,80 por 3,60 m. Está realizada con una fábrica mixta de ladrillos y sillares (lám. 1). Los ladrillos muestran en su mayoría formato romano. Los sillares, en cambio, presentan una amplia dispersión métrica oscilando entre los 1,60 por 0,46 por $0,56 \mathrm{~m}$. y los 1,12 por 0,54 por $0,58 \mathrm{~m}$. La naturaleza de estos materiales es principalmente caliza predominando el tipo que se denomina "conglomerado". Se trata, por tanto, de piedras que pueden localizarse fácilmente en las proximidades del lugar. Por lo general, son piezas bien cortadas, de alisado muy desigual y dispuestas sin tener en cuenta los lechos de cantera. No existe una disposición exclusiva en su colocación aunque se aprecia una intención definida por situarlas de manera alternante a soga y tizón. Estas piezas se encuentran unidas unas veces por medianos intersticios cogidos por una argamasa marronácea muy endeble y, en otras ocasiones, por gruesos tendeles entre los que se llegan a colocar ladrillos de canto correctamente dispuestos. En el paramento occidental pueden apreciarse, a cota de suelo, una serie de sillares que muestran unas anchas y profundas ranuras transversales y perpendiculares a la línea delantera. Se trata, sin duda, de las improntas que, a modo de durmiente, dejó algún tipo de cierre. Este sería el único acceso posible al interior de la sala, de modo que no existiría comunicación directa entre esta cámara y el ábside.

Dentro de esta estancia se localizaron huellas muy desiguales de algunos de los elementos que se distribuían originariamente en su interior. Desgraciadamente, ninguna información hemos obtenido del pavimento que debía recubrir el piso a excepción de un solado horizontal situado en la esquina noroeste de la sala. Este firme ocupa, a modo de cuarto de círculo, una superficie de 1,20 m. Está realizado con pequeñas piedras y su límite exterior se marca mediante fragmentos de ladrillos colocados de canto. No obstante, lo más destacado fue el descubrimiento en el centro exacto del habitáculo de la mitad de un fuste liso de mármol rosáceo depositado sobre el suelo (lám. 2). Esta columna descansaba directamente sobre dos hiladas de trozos de ladrillos. Justo encima y perfectamente alineado se halla un pequeño hoyo circular de escasa profundidad también delimitado por fragmentos de ladrillos. Debajo de la columna no se encontraron restos arqueológicos algunos, ya que inmediatamente aparecía la tierra natural; en cambio, en el interior de la pozuela pudimos localizar algunas muestras de carbón y un pequeño fragmento de vidrio.

La estancia que nos queda por describir se desarrolla al norte de la anterior. De ella, sólo se conserva su mitad meridional; esto es, un espacio casi cuadrangular de 2,30 por 2,50 m. Los límites exteriores de esta habitación los constituye un paramento de sillares de la misma naturaleza que los anteriores pero de 
diferentes características técnicas. El sistema constructivo empleado en esta parte del edificio es, con diferencia, bastante más cuidado que en la sala lateral. Aquí los sillares se encuentran perfectamente cortados, con aristas vivas, dispuestos de forma regular y unidos entre sí por medio de finos intersticios de cal que a veces ni se aprecian pareciendo estar los materiales colocados "a sangre". El ábside constituye, por tanto, una obra de sillares sumamente cuidada que contrasta con el resto de las construcciones. Su pared presenta un grosor que oscila entre los 0,87 y $0,70 \mathrm{~m}$ y está formada por dos hiladas sucesivas de sillares. Toda la habitación originariamente se encontraba pavimentada con una gruesa y cuidada capa de opus signinum cuya superficie exterior mostraba un intenso y uniforme color rojizo. Por último, justo en el extremo norte de este cuarto y unido al muro de la exedra se localizó a la cota suelo una obra de 0,35 por $0,47 \mathrm{~m}$ realizada con fragmentos de ladrillos cogidos con un mortero de cal semejante al que une los sillares. La disposición de los ladrillos ligeramente inclinados no ofrece duda que se trata del lanzamiento de un pequeño arco en dirección oeste.

Los muros de ambas estancias conservan un alzado medio de un metro aproximadamente y todos ellos tienen una cimentación consistente en un conglomerado muy compacto y duro de cal, fragmentos de ladrillos y piedras sobre el que se disponen dos hiladas superpuestas y corridas de sillares.

Para finalizar la descripción del edificio nos queda por estudiar un muro de sillares que avanza un par de metros desde el final de la cabecera en dirección oeste. Se trata de la prolongación de la medianera de las dos salas del presbiterio. Tiene una orientación de $80^{\circ}$ nordeste. Constituye, por tanto, el único vestigio de las naves de la iglesia que se ha conservado. Sus características tecnológicas y métricas son iguales a las vistas en las paredes de la habitación meridional. La mayor parte de esta estructura corresponde a la cimentación de la nave sur, a excepción de la zona colindante con la cabecera de la iglesia donde se aprecia una pilastra de sillares que sobresale del paramento unos $0,40 \mathrm{~m}$. y mantiene un alzado de 0,37 $\mathrm{m}$. No obstante, en el proceso de excavación aparecieron algunos fustes muy destruidos y una basa que nos inclina a considerar que el cuerpo de la iglesia se sustentaría mediante hiladas de columnas que en los extremos de la sala se recogerían en sendas pilastras para mayor estabilidad de la edificación.

\section{ANÁLISIS DE MATERIALES.}

Incluimos en este capítulo una relación de los materiales aparecidos en el área de la basílica. Se trata de una colección poco homogénea, de piezas de distinta naturaleza y funcionalidad que muestran un estado muy desigual de conservación. La mayor parte de ellos fueron recuperados durante la excavación o cuando tuvieron lugar las obras de explanación de la plataforma superior. Dentro de estos hallazgos se incluyen piezas cuya secuencia estratigráfica está correctamente documentada junto a otras prácticamente descontextualizadas pero cuya vinculación al templo no ofrece duda. También dentro de este último grupo hemos agregado algunos ejemplares depositados en la Fundación Cultural Fernando Villalón y en el Museo Provincial de Sevilla que originariamente pertenecían al complejo religioso.

\section{- Cancel.}

Se localizó dentro de un paquete estratigráfico donde aparecieron además restos de tumbas, esqueletos, materiales arquitectónicos, etc. Se trata de un bloque casi cuadrangular de $0,84 \mathrm{~m}$ de altura por $0,71 \mathrm{~m}$ de anchura y apenas $0,25 \mathrm{~m}$ de grosor (lám. 3). Está realizada en la misma caliza en que se tallaron los sillares del ábside y el sarcófago. Presenta decoración únicamente por su cara frontal. La composición se distribuye en dos recuadros de iguales dimensiones que repiten exactamente el mismo esquema ornamental; a saber: enmarcadas por columnas torsas que en los extremos inferiores parecen descansar sobre plintos se dispuso, abarcando algo más de las tres cuartas partes de la pieza, una decoración de círculos secantes de igual radio 
que al cortarse originan rosetas de cuatro pétalos. Coronan ambos paneles arcos semicirculares que se suceden en número de siete. Este frontón queda encerrado en sus extremos laterales por dos cenefas de tallos vegetales ondulados.

Esta placa, al conservar prácticamente intactos sus cuatro bordes, nos ofrece una interesante información sobre algunas peculiaridades de su morfología. El cancel lleva lengüetas en las caras laterales que ensamblarían en las ranuras de las barroteras de sujeción. En el frente superior se practicó una leve ranura que abarca buena parte de su superficie que tal vez pueda ponerse en relación con las piezas de ensamblaje horizontales, si interpretamos este rebaje como una preparación para recibir otra pieza de remate. El borde inferior lo constituye un plano completamente horizontal por lo que parece que debería descansar directamente en el suelo.

\section{- Ladrillos.}

Durante los trabajos de limpieza de algunas áreas de la basílica se localizaron una serie de niveles alterados por remociones bastante antiguas, en cuyo interior pudo recuperarse un interesante conjunto de materiales, muchos de los cuales habían pertenecido primitivamente a la iglesia. Entre estos materiales cabe destacar la aparición de tres fragmentos de ladrillos decorados (láms. 4 y 5). Se trata de piezas cerámicas, de cocción uniforme y oxidante con vastos desgrasantes vegetales y minerales; cuyas paredes, a excepción de la cara frontal, muestran un alisado exterior muy desigual y poco cuidado. Todos pertenecen a un único formato de $0,39 \times 0,25 \times 0,45 \mathrm{~m}$ con muy escasa dispersión, salvo en el espesor que oscila entre los 0,04 y $0,05 \mathrm{~m}$. En los extremos superior e inferior de la pieza siempre se desarrollan dos anchas lengüetas lisas, sin decoración de unos $0,065 \mathrm{~m}$ de altura.

Los temas, representados en relieve, están realizados a molde. Los motivos son siempre los mismos ': en el centro, y dominando toda la composición, un gran crismón con $P$ cerrada flanqueado por los signos alfa y omega y con dos estrellas de siete puntas en la parte inferior. Encierra este motivo dos columnas con plinto y capitel rematadas por un arco de medio punto en cuyo interior se alberga una venera de doce gallones. En las enjutas aparecen delfines muy estilizados. A ambos lados de las columnas y en sentido longitudinal a la decoración se desarrolla una inscripción, también a molde, donde puede leerse en el lado izquierdo SALVO EPISCPO y en el derecho MARCIANO.

\section{- Placa cerámica.}

Corresponde a la parte final de un epígrafe del que existen serias dudas sobre su lugar de aparición a pesar de lo cual hemos optado, con las reservas oportunas, incluirlo aquí. Se trata de una placa rectangular de cerámica que ha llegado a nosotros fracturada por su parte anterior por lo que desconocemos cuáles serían sus dimensiones completas y el epígrafe al que hace alusión. El fragmento se halla enmarcado por arriba y por abajo por dos líneas superpuestas en zig-zag en relieve y en el centro puede leerse "TORVM". Solo se ha conservado, por tanto, la partícula del genitivo plural -orum- por lo que no podemos saber el significado de la palabra. Las letras se hallan bien trazadas perfectamente individualizadas. Son capiteles cuadradas, de acusado remate, la $\mathrm{R}$ cerrada, los ángulos de la $\mathrm{M}$ cortos y el trazo horizontal de la $\mathrm{T}$ alargado. Según J. González es posible que delante figurase un vocablo como RELIQVIAE siendo un ejemplar único en la epigrafía hispana (González Fernández 1996: 245-246).

1. Piezas con motivos decorativos completos pueden verse en (Martín 1982). 


\section{- Revestimientos.}

Se trata de varias placas parietales recuperadas durante la excavación de la habitación meridional de la cabecera en los niveles correspondientes al abandono y ruina de la iglesia. En este sentido, no hay duda, tanto por el sitio exacto donde fueron halladas, como por los estratos en los que se encontraban, que todas ellas debieron, en su momento, formar parte del recubrimiento de las paredes de la primitiva basílica. Por lo general, son piezas muy fragmentadas que solo conservan una mínima parte de la decoración por lo que no es posible conocer las representaciones concretas a las que pertenecen. Constituyen un conjunto bastante heterogéneo de materiales por lo que serán descritos de manera individualizada.

- Dos finas placas de mármol blanco de unos cuatro centímetros de espesor perfectamente alisadas por su cara frontal mientras que la dorsal muestra numerosas irregularidades.

- Realizada con barro amarillo, muestra una decoración consistente en dos grupos de gruesas líneas incisas paralelas entre sí y dispuestas en sentido vertical separadas por una estrecha franja de dos centímetros de grosor de finas incisiones horizontales.

- Revestimiento de ladrillo rojo bastante grueso que presenta en su cara frontal una decoración organizada en casetones en cuyo interior se distinguen series de incisiones orientadas en cada recuadro de diferente sentido. Están separados por líneas también incisas aunque mucho más anchas y profundas.

- Se trata de dos placas cerámicas de reducidas proporciones una de las cuales muestra en uno de los frentes laterales una ranura estrecha y rectangular mientras que la otra posee una fina lengüeta. Ambas piezas podían machihembrarse perfectamente.

\section{- Sarcófago.}

Apareció justo delante de la sala meridional de la cabecera casi pegado al hueco de entrada a dicha sala. Se trata de un sarcófago liso, realizado en caliza, bien labrado y de aristas exteriores redondeadas. Puede que se trate de una estructura reaprovechada aunque no podemos confirmar tal extremo. En la mitad inferior aproximadamente del costado sur se abrió un orificio que atraviesa toda la pared. No han quedado restos de la cubierta. Enmarcando el sarcófago se encuentra al sur una hilada de lajas y ladrillos rotos bien alineados y al norte una serie de grandes sillares. Ambas estructuras parecen conformar las paredes laterales de la tumba; de modo que el sarcófago debió funcionar dentro de este conjunto funerario como ataúd

\section{- Campana.}

Se halla expuesta en la sala dedicada al período visigodo del Museo Arqueológico Provincial de Sevilla. Pertenece a la colección Rabadán y, según consta en el libro de registro, procede de la ciudad de Morón de la Frontera, por lo que no hay duda que debió pertenecer al complejo religioso que estamos estudiando. Se trata de una pieza de hierro bastante sólida y en un perfecto estado de conservación (lám. 6). Tiene una altura máxima de $0,25 \mathrm{~m}$. y el diámetro inferior es de $0,30 \mathrm{~m}$. Las únicas decoraciones que muestra son una serie de bandas en relieve, apenas salientes, que en número de tres -dos en la parte superior y una a tres centímetros del borde inferior- se reparten en la cara exterior de la pieza. Encima de las bandas se encuentran dos hiladas superpuestas de tres y cuatro orificios respectivamente. 


\section{CONSIDERACIONES GENERALES.}

Tradicionalmente se considera que el tipo de iglesia con cabecera de fondo plano y flanqueada por dos cámaras laterales tiene su origen en el norte de Siria a través de los santuarios nabateos de la Siria del Sur. A la Península penetraría por el norte de África (Palol 1967: 27-28). La teoría de las cabeceras siriacas -como se denomina a este tipo- fue aceptada por la mayoría de la crítica arqueológica. No obstante, Krautheimar, en el estudio que realiza sobre la iglesia de Tebessa (Argelia), difiere de esta teoría y comenta que "Difícilmente pudo Tebessa inspirarse en modelos sirios para las cámaras laterales. Al parecer, los arquitectos norteafricanos habían desarrollado independientemente estas cámaras laterales en el siglo IV, seguramente derivaran de modelos constantinos"(Krautheimar 1984: 227). Entre distintos investigadores que se ocuparon de las iglesias de cabecera tripartitas peninsulares sólo T. Ulbert (Fernández 1987: 187) manifestó que los precedentes de este modelo arquitectónico habría que buscarlos en edificios romanos imperiales profanos sin necesidad de acudir a prototipos de origen sirio de época cristiana.

No obstante, lo que más llamó la atención fue la ubicación de dos cámaras tan cercanas al santuario. La función de estas dos salas era, sin duda, lo que determinaba la forma de la cabecera; de ahí que su estudio gozase de una favorable acogida entre los investigadores que trabajaban en este tipo de iglesia. Los primeros datos documentales aducidos se establecieron en relación con la liturgia bizantina donde se usaban dos pastophoria laterales. La meridional correspondía al diakonikon y se destinaba a las ofrendas de los fieles (Palol 1967: 5). Esta teoría, aceptada sin reparo por la mayoría de los arqueólogos, se establece sobre argumentos anacrónicos ya que se estaba extrapolando para momentos paleocristianos elementos de época medieval. R. Puerta, en su estudio sobre las iglesias hispánicas, comentaba que en España no aparece en los textos de aquel período referencia alguna a las prothesis ni diakonikon suponiendo que las funciones de aquéllas las realizarían las que llaman nuestros textos preparatorium y sacrarium, correspondiendo a este último las funciones del diakonikon, al ser lugar destinado para las cosas sagradas (Puertas 1975: 164-136).

C. Godoy, ahondando en el tema iniciado por R. Puertas, ha realizado un detallado estudio de las fuentes hispánicas escritas de la época para averiguar qué denominación reciben estas cámaras y que función le asignan los textos (Godoy 1975: 88-103). Las fuentes hablan del sacrarium y el thesaurum como espacios litúrgicos que pueden identificarse como ámbitos cercanos al santuario. Sobre la base de los datos obtenidos concluye que en el esquema arquitectónico tripartito resulta difícil determinar la funcionalidad de las cámaras que flanquean el ábside. Siendo imprescindible para la liturgia la presencia de un sacrarium, podría identificarse con una de estas dos cámaras, en el caso probado que exista una buena accesibilidad entre ésta y el santuario. En la iglesia de Morón esta posibilidad queda descartada ya que, como hemos visto, no existe comunicación directa entre la sala lateral y el ábside. El thesaurum, por su parte, constituye un ámbito excepcional -cuya presencia no es vinculante a las ceremonias litúrgicas-donde se depositan los tesoros más preciados de la iglesia. Por tanto, no todas las iglesias poseerían un thesaurum. Serían, incluso, escasas las que contarían con elementos de valor suficiente para habilitar una espacio específico para ellos. En estos casos las piezas relevantes se guardaban en el sacrarium.

A tenor de estos datos algunas cuestiones se pueden precisar sobre nuestra habitación meridional. En el centro de la cámara y recogido por una obra de ladrillos se halla un fuste de columna (lám. 2). El análisis de esta pieza, dada su situación principal y dominante, nos permitirá acercanos a la posible funcionalidad de esta sala. Dos hipótesis se pueden enunciar para explicar esta cuestión y en ambas esta cámara tendría la misión de thesaurum.

Según Donceel-Voûte, un elemento para la identificación de una de las cámaras laterales como lugar de depósito del tesoro es la presencia de puerta -y no de arco- que permitiera custodiar con seguridad los objetos preciosos. En este sentido, ya comentamos que a la sala lateral de la iglesia de Morón sólo es 
posible acceder por una puerta abierta en el frente que mira hacia las naves de la basílica ${ }^{2}$. Por otro lado, justo delante de esta cámara se encuentra un enterramiento en sarcófago. "El uso de sarcófagos, de clara tradición antigua, debía estar reservado a gente importante por cuestión de jerarquía o fortuna. Los escasos ejemplos que han quedado son de obispos o santos" (Puertas 1975: 133). En la actualidad esta afirmación quizás deba matizarse a la luz de los últimos hallazgos arqueológicos. No obstante, sea como fuese, el carácter excepcional que muestra el sarcófago en nuestra iglesia donde el resto de los enterramientos, tanto de esta época como de posteriores, son de piedras y materiales reaprovechados pone de manifiesto que debía reservarse para inhumación de un personaje singular y, por tanto, dentro de la iglesia ocuparía necesariamente un lugar principal. En este caso, su situación delante de la sala evidencia claramente el papel tan destacado que ésta debió tener en el conjunto eclesiástico así como su funcionalidad peculiar y exclusiva que no permite, como ocurre en otras basílicas, que el enterramiento por importante que fuera se disponga en su interior ${ }^{3}$.

Ahora bien, los tesoros más preciados de la iglesia, en todos los sentidos, fueron las reliquias de sus mártires. Así, en la iglesia emeritense de Santa Eulalia había una sala llamada thesaurum donde se guarda la túnica de la mártir Eulalia ${ }^{4}$. Fuera de la península nos interesa citar la iglesia de Santa Sión donde en una de las salas que flanqueaba el ábside, concretamente la meridional, aún podían contemplarse en el siglo VI las piedras de lapidación de San Esteban (Godoy 1990: 335-387).

En este sentido, cabe la posibilidad de que esta columna hiciera alusión a un santo del que no nos ha quedado testimonio alguno ${ }^{5}$. A este respecto, debemos recordar la popularidad que alcanzó durante buena parte de la Alta Edad Media el movimiento estilita en el cristianismo. El agujero de escaso diámetro y profundidad que se abre en el pavimento justo en la cabecera de la columna puede tener distintas interpretaciones y una de ella, relacionada con lo anterior, puede tratarse de una pequeña fosa de reliquia por lo que nos encontraríamos que este edificio podría corresponder a una posible memoria o un martyrium. Es interesante comprobar que en el interior de este posible relicario, bastante alterado por haber sido expoliado en época antigua, se encontró un fragmento de vidrio perteneciente probablemente a un recipiente pequeño. También, con relación a este tema hay que señalar la existencia en los fondos de la Fundación Fernando Villalón de una placa de cerámica en la que aparece escrita en capitales cuadradas la palabra TORUM. Dicha placa procede de los alrededores de Morón aunque no es posible precisar el lugar exacto. En este sentido, no sería arriesgado suponer que pudo pertenecer originariamente a nuestra iglesia habida cuenta que no se encuentran yacimientos adcribibles a época tardorromana-visigoda en las proximidades de la ciudad. J. González piensa que "es posible que delante figurase un vocablo como RELIQVIAE.", lo que la constituiría en un ejemplar único de nuestra epigrafía (González Fernández 1996: 245-246). Esta hipótesis, de ser cierta, corroboraría aún más nuestra interpretación. No obstante, a tenor de los datos de que disponemos, nada concreto podemos afirmar, de modo que todas estas interpelaciones sólo pueden ser planteadas en términos de conjeturas.

Tampoco hay que olvidar el culto bastante extendido que tenían las columnas en las religiones precristianas de Hispania (Blázquez 1975). Hasta tal punto llegaba la veneración por estas piezas que durante los primeros siglos del cristianismo entraron de manera activa a formar parte de las manifestaciones rituales cristianas como una reminiscencia clara del paganismo. La cuestión llegó a estar tan extendida que la jerarquía

2. Una disposición idéntica a nuestra sala con puerta en el frente oeste se localiza en la cámara meridional y ábside de la iglesia de Es Cap des Port (Fornells, Menorca) siendo interpretada, con las consiguientes reservas y en base a los argumentos antes expuestos, como un posible thesaurum. (Godoy 1995: 170-172).

3. En algunas iglesias las cámaras laterales son empleadas como espacios funerarios como son los casos, por ejemplo, de Santa Margarida del Priorat de Sant Genis de Rocafort, El Bovalar de Lérida, etc.

4. En ocasiones estas reliquias podían quedar custodiadas igualmente en el sacrarium.

5. El culto a los mártires tuvo en Occidente un gran esplendor hasta el punto que llegó a provocar más devoción que los sacramentos de la iglesia como atestigua el hecho que se tuviera que legislar en repetidas ocasiones contra ello. 
eclesiástica se vio obligada a legislar en términos muy duros ante el preocupante cariz que estaba tomando el asunto, como demuestra el canon 59 del concilio de Elvira:

\section{"Prohibendum ne quis christianus, ut gentilis, ad idolum capitoli causa sacrificandi ascendat et videat..."}

La abundante legislación que sobre este asunto se ha conservado y las condenas cada vez más rotundas que en ellas se expresan indican que el culto a las columnas se hallaba aún muy enraizado en las gentes que no parece, por otro lado, que aún tuvieran muy asumida la fe cristiana. Es patente, por tanto, que la estricta fuerza de los cánones no serviría para erradicar éste y otros problemas que en el mismo sentido tendría planteada la iglesia de aquellos tiempos con las antiguas prácticas paganas ${ }^{6}$ que, como muy bien expresa el III Concilio de Toledo en su canon 16, aún se hallaban muy extendidas por toda la Península y la Galia:

“Quoniam pene per omnem Spaniam siue Galliam idolatriae sacrilegium inoleuit..."7

Hay que indicar también que el fenómeno del paganismo se hallaba bastante más arraigado entre las poblaciones rurales y ello estuvo favorecido por la aparente permisividad de algunos obispos hacia aquellas prácticas $^{8}$.

Por todo ello, la iglesia se vio obligada a tomar una solución menos ortodoxa pero mucho más eficaz. Esta no fue otra que cristianizar progresivamente los residuos de paganismo salvo que entrasen en abierta contradicción con la doctrina cristiana, esmerándose, por tanto, en imprimirles su sello. Para ello se valió de distintos y hasta contrapuestos procedimientos (Hillgarth 1980: 3-60). Así por ejemplo se procedió a construir templos en numerosos lugares donde se desarrollaban cultos profanos (Dalmais 1967). También fueron abundantes las actividades paganas que pasaron a formar parte, sin el menor reparo, del ritual cristiano $\mathrm{e}$, incluso, determinadas festividades profanas se incorporaron, con total inverecundia, a su almanaque (Laurentin 1967). Dentro del culto a las columnas que es la cuestión que nos ocupa tenemos un ejemplo evidente de lo que estamos comentando: el Pilar de Zaragoza. En el costado del río Ebro se encontraba muy popularizada la veneración a una columna. El cristianismo para erradicar definitivamente esta devoción instaló justo encima una cruz. Después ya en plena Edad Media se extendió la historia de la virgen y el pilar (Borras i Feliu 1982: 281-295).

El ábside, como hemos comentado, es de sección semicircular pavimentado, como es común en este tipo de iglesia, con una gruesa placa de opus signinum ligeramente realzado respecto al suelo de la habitación lateral y no sabemos si se extendería también al primer tramo de la iglesia, ya que parece continuar, aunque este extremo no se puede precisar. En caso de que así fuese, podía prolongarse hasta el límite de los canceles como ocurre en la iglesia de Son Bou. En los restos de pavimento conservados, que es prácticamente la mitad meridional de este espacio, no se hallan huellas de stipites por lo que no sabemos dónde se hallaría el altar o si estuvo ligeramente adelantado.

6. El XII Concilio de Toledo dedica su canon 11 a De cultoribus idolorum lo que demuestra que, aún a fines del siglo VII, las prácticas idolátricas seguían constituyendo un grave problema pastoral.

7. Denuncias parecidas acercas de la extensión que todavía conservaban las prácticas paganas en nuestro suelos pueden verse en los cánones XIV y XV del Concilio de Narbona del 589; un siglo después, en el canon XI del Concilio de Toledo del 681. En las postrimerías del siglo VII, concretamente en los Concilios XVI y XVII de Toledo fechables en los años 693 y 694 respectivamente, se vuelve a hablar del tema, incluso en el primero de ellos es el propio rey Egica quién exhorta a radicar estas prácticas. (Vives 1963)

8. Las alusiones a este tema en el XVI Concilio de Toledo son bastante claras. 
Algunas cuestiones respecto a las técnicas edilicias empleadas en la construcción de la iglesia se pueden comentar. Se han constatado dos tipos de aparejos: uno de hiladas corridas de sillares que se documenta en la zona del ábside y del crucero y otro que emplea sillares de escaso ajuste métrico entre cuyas piezas se localizan obras puntuales de mampostería y ladrillos como puede verse en la habitación lateral. El primer grupo va a ser característico de una serie de ábsides de la segunda mitad del siglo VI como la basílica de Segobriga, San Pedro de Mérida, Villa Fortunatus, la basílica del anfiteatro de Tarragona, etc. No obstante, lo que más nos interesa destacar es la utilización masiva de la sillería en nuestra obra ${ }^{9}$ que no puede explicarse, como en otros casos, por una reutilización de materiales procedentes de edificios anteriores pues sencillamente estos no se documentan en el cerro del Castillo ni en sus proximidades. La otra explicación sería que estas piezas fueran labradas in situ y ex professo para nuestra basílica. Esta posibilidad plantea el desplazamiento a nuestra zona de canteros ya que equipos estables de talla de sillares, como apunta Kingsley, parece que únicamente se mantienen en centros urbanos importantes como son los casos de Mérida, Tarragona, Recopolis, etc. (Olmo 1988: 157-178).

La diferencia edilicia entre el ábside y la cámara lateral puede explicarse desde un punto de vista estrictamente constructivo. Así podemos apuntar, como hipótesis, que sobre los anchos y sólidos muros de sillares del ábside se pudo elevar una bóveda mientras que la obra de sillares, mampostería y ladrillos menos uniforme posiblemente estaba cubierta por el entramado de un techo de madera cerrado por un tejado.

De la nave de la iglesia tan sólo se han conservado algunas hiladas de sillares que avanzan un par de metros en dirección oeste. Estos restos parecen indicar que debió tratarse de una cimentación corrida de piedra sobre la que se elevaría a tramos regulares una serie de columnas de mármol de cierta entidad como demuestra los restos de basas circulares localizado a lo largo de la excavación (fig. 3). Todo ello da una idea certera de la entidad de la obra ${ }^{10}$.

A pesar de los escasos vestigios arquitectónicos que nos han quedado, algunos paralelos podemos establecer al respecto. Una disposición similar a la nuestra la encontramos en Son Peretó de Mallorca. Según Palol originariamente la iglesia sería de cabecera rectangular saliente por el exterior, de modo que las dos naves laterales son producto de una reforma posterior que afectó a esta zona de la iglesia y al baptisterio (Palol 1989: 1975-2022). Godoy discrepa de esta apreciación y piensa que todo el complejo religioso es del mismo momento, debiéndose las anomalías constructivas a peculiaridades edilicias o al pésimo estado de conservación que presenta el edificio (Godoy 1995: 158). Sea como fuere, en ambos casos la construcción de la basílica puede fecharse ampliamente en la segunda mitad del VI.

En Menorca el paralelo más exacto lo hallamos en Son Bou. No existen argumentos arqueológicos para su datación, de manera que las únicas hipótesis al respecto se basan en motivos estilísticos. Algunos autores, como es el caso de Palol, proponen una fecha del siglo VI mientras que otros, como Schlunk y Hauschild, sitúan el edificio en el siglo VII. La cámara sur puede identificarse como sacrarium y posiblemente también como martyrium (Godoy 1995: 178-179). Otro ejemplo de cabecera tripartita, aunque no tan idéntica a la nuestra como en el caso anterior, se encuentra en Es Cap des Port en Menorca (Palol 1982: 353-404). Sobre la base de los materiales aparecidos en la excavación se propone una datación de inicios del siglo VI. En el ábside de la iglesia fue localizada una cripta en forma de cruz griega de gran interés desde el punto de vista litúrgico. La cámara que flanquea por el sur al sanctuarium recibe, en cambio, distintas interpretaciones. Así, para Palol tiene un uso funerario quizás relacionado con un culto martirial, mientras que para Godoy posiblemente formaría parte del thesaurum (Godoy 1995: 170-172). La iglesia de Es Fornás de Torelló, también en Menorca, al igual que nuestra iglesia sólo conserva la habitación lateral y el ábside -en este

9. En nuestro edifico junto a las piezas de la iglesia hay que incluir las que aparecieron esparcidas a lo largo de las otras dos bancadas, en la necrópolis medieval y en el basamento de algunas torres.

10. Algunos de los fustes localizados en el interior de los paños del castillo podrían con seguridad corresponder a los soportes originarios de la iglesia. 
caso completo-que no muestra en su interior el característico trazado semicircular. A falta de otros elementos Palol propone, basándose en el estilo de los mosaicos, la segunda mitad del siglo VI para su construcción (Palol 1967: 18-23).

En la Tarraconense dos paralelos se pueden argumentar. El Bovalar (Palol 1994:3-40) en Lérida fechado en el siglo $\mathrm{V}$ y cuyo ábside tiene forma rectangular en el interior. La sala sur tuvo un claro uso funerario como demuestran los tres enterramientos que se localizaron en su interior. La iglesia de Santa Margarida del Priorat (Navarro y Mauri 1994: 341-344) en Martorell de finales del siglo VI o principios del VII, como atestigua su ábside en forma de herradura, aunque de cabecera plana flanqueada por dos cámaras muestra ciertas peculiaridades formales que obligan a tomarla con reservas dentro de este grupo.

En la Bética el ejemplo más próximo lo encontramos en la iglesia de la Huerta de Nicomedes en Sevilla. Los excavadores (Fernández et alli 1986: 41-50) proponen como fecha de construcción a principios del siglo VI basándose en el canon 18 de I Concilio de Braga (561) que prohíbe los enterramientos en el interior de las iglesias. Palol critica esta propuesta de datación y propone una algo más tardía sobre la base de que todos los enterramientos pueden adscribirse al siglo VI (Palol 1991: 271-428).

A continuación pasaremos a comentar algunas cuestiones acerca del sepulcro rectangular tallado en piedra. Este se encontraba rodeado por los gruesos sillares de la cimentación de la nave y la cámara y por un modesto muro de ladrillos. La existencia de una estructura muraria circundante y su disposición con respecto al sarcófago nos inclinan a considerar que ésta debió constituir los límites de la fosa propiamente dicha mientras que el sepulcro en piedra que se albergaba en su interior haría las veces de féretro.

Otra cuestión interesante sobre esta tumba es la existencia de un pequeño orificio que pudo formar parte de los restos de un conducto de libaciones. La presencia de estos conductos en la Península, aunque no es muy frecuente, tampoco se trata de un elemento funerario raro. Estos conductos de libaciones que mantenían abierta una comunicación entre vivos y muertos se realizan a través de unos tubos pequeños, en forma de jeringa, que iban desde la superficie del suelo hasta el interior de la tumba atravesando sus paredes, aunque en nuestro caso no sería necesario, ya que el agujero en la piedra del sepulcro permitía conducir correctamente el líquido a su destino. Se documentan desde fechas bastante tempranas en cementerios cristianos (Marcos 1961: 90) y se mantuvo durante un marco cronológico bastante dilatado y en un ámbito geográfico bastante amplio. En la Península, y realizados en los más diversos materiales, se localizan en Itálica, Mérida, Tarragona, etc. No obstante, los que más nos interesa destacar son los hallados en Carmona (Bendala 1976: 36 y 124), en Mérida (Marcos 1961: 90) y en la basílica de Son Bou ${ }^{11}$, ya que en los tres casos se trata de sarcófagos, como en el nuestro, con perforación para posibilitar las libaciones. Las libaciones se llevaban a cabo no sólo durante los días que seguían al entierro sino también en los aniversarios. De este modo, los conductos, aunque camuflados, podrían delatar la presencia de las tumbas por lo que estarían más expuestas al expolio. Probablemente, éste sería el motivo por lo que paulatinamente se fue abandonando esta práctica. En este sentido, es interesante constatar cómo de todas las tumbas recuperadas en nuestra necrópolis ésta es la única que había sido saqueada íntegramente.

Respecto a la organización interior de la iglesia el único elemento que se ha podido recuperar fue un cancel macizo o plutei cuya decoración principal se desarrolla en su cara frontal y consiste en círculos secantes de igual radio que originan al cortarse entre sí rosetas de cuatro pétalos. Esta temática es con diferencia la más difundida en el repertorio ornamental visigodo. Palol presentó su evolución a partir del mosaico romano y en escultura arquitectónica aparece en la primera mitad del siglo VI (Palol 1967: 252-255). Todos los talleres hispánicos reprodujeron este motivo con interpretaciones muy variadas e incluso en los escasos testimonios que nos han quedado de la orfebrería de aquellos momentos se encuentran ejemplos de esta temática como en la corona de Recesvinto del tesoro de Guarrazar. Los círculos secantes parecen

11. Este sarcófago se halla en la actualidad expuesto a los pies de la iglesia. 
de influencia toledana ya que aunque también hay piezas procedentes de la metrópolis emeritense, por lo general su aplicación en aquella escuela se ciñe fundamentalmente a cimacios, impostas y piezas cuyo espacio compositivo es bastante limitado.

La composición del panel en dos recuadros rematados por arcos sostenidos por columnas con una red de círculos imbricados o en abanicos es muy común en los canceles visigodos documentándose ampliamente incluso en la escuela de Mérida, aunque con una decoración interna, como puede verse en los ejemplos conservados en el museo de Mérida (Cruz Villalón 1985: láms. 115-145). Por otro lado, el espacio interior que conforman los arcos que coronan la composición casi siempre se rellena con veneras o se deja libre por lo que la decoración basada en círculos concéntricos supone una novedad que quizás haya que atribuir a cierto carácter local, lo que apoya que el tipo de material empleado provenga de una cantera local.

A pesar de que son pocos los canceles o las huellas que de los mismos se han conservado conocemos con cierta precisión sus principales funciones gracias al estudio de Schlunk (Schlunk 1971: 503-523). Los canceles tienen como misión acotar espacios dentro de la iglesia en orden a su organización jerárquica, a prescripciones litúrgicas o particularidades ceremoniales. Desgraciadamente, durante el proceso de excavación de nuestra iglesia, sólo pudo recuperarse un cancel volcado en el primer tramo de la iglesia delante del santuario. Ahora bien, a tenor de ciertos datos obtenidos en los restos murarios de la iglesia podemos apuntar algunas hipótesis sobre la primitiva conformación de estos elementos. El lugar donde se localizó el cancel indica que éste debía emplearse para separar el chorus, situado en el primer tramo de la iglesia, del resto de la nave. Por otro lado, parece que los canceles debían delimitar únicamente el primer tramo de la nave central ya que precisamente la existencia de un vano de acceso en la sala lateral al ábside no puede explicarse si no es ligada a la libre circulación de los fieles lo que haría necesaria una puerta que protegiese los restos que allí se hallaban depositados. En este sentido, las hipótesis que apuntábamos acerca de la posible funcionalidad de esta cámara implica obligadamente la posibilidad de los fieles de acceder hasta el mismo umbral de la sala. En consecuencia, podemos identificar el espacio del sanctuarium y del chorus con el ábside y el primer tramo respectivamente de la nave central como ocurre también en las basílicas de Son Bou, Son Peretó y Es Fornás de Torrelló, todas ellas en las Baleares.

Mención aparte merecen los ladrillos de la serie de "Marciano" localizados en las excavaciones. Las placas cerámicas constituyen uno de los conjuntos ornamentales más difundidos en los tiempos paleocristiano y visigodo. Para Palol se trata “... de un elemento originariamente no hispánico que toma inmediatamente carta de naturaleza en la Bética y tiene un desarrollo amplísimo y original en la actual Andalucía. Su origen africano está claramente demostrado por la existencia de piezas de taller del norte de África, concretamente Beja, Cartago o Lamniana... Sabemos, además, que la influencia de estas placas de cerámica decoradas en relieve no está patente únicamente en Hispania sino que aparecen,... en Francia y en Bélgica..." (Palol 1967: 229). Efectivamente estos ladrillos se dan en el norte de África, aunque por el momento no se puede establecer con certeza si existe una dependencia entre ambos focos, ya que las piezas que aparecen en las Baleares, que están directamente vinculadas con producciones de Túnez, etc., son producto de una relación directa que aún queda por demostrar si se da en la Península.

A pesar de que contamos con una amplia colección de plafones decorados, ninguno de ellos se ha encontrado en contexto estratigráfico, por lo que no es posible determinar su exacta funcionalidad. En este sentido, la opinión más extendida le confiere un carácter funerario o sencillamente de "exvotos" (Schlunk 1947:235), mientras que son también numerosos los que los consideran como decoraciones parietales (Corzo 1989: 22).

No hay duda, según recientes estudios, que tanto la serie "Marciano" como otras placas cerámicas decoradas se fabricaron en un taller próximo situado en los actuales terrenos de Balbuan ${ }^{12}$. El considerable

12. Otros talleres que fabricaron también plafones decorados se hallan en Ronda (Málaga) y Jerez de la Frontera (Cádiz) (Palol 1991: 340). 
número de ladrillos decorados y los distintos moldes localizados en aquel yacimiento así lo confirman. Debió tratarse, a juzgar por los restos aparecidos en aquel sector, de un pequeño taller familiar en un hábitat rural perteneciente a una modesta aldea o a una gran propiedad pues no es posible documentar en este sector ninguna ciudad. Los materiales recogidos durante la prospección de Balbuan permiten adscribir el yacimiento a los siglos III-VII. Funcionaría, por tanto, durante toda la Antigüedad Tardía y el período visigodo lo que supone una prueba más de la continuidad del mundo tardorromano en nuestra zona, máxime cuando examinamos los repertorios iconográficos de estos materiales o incluso detalles técnicos como las dimensiones. La difusión de estas cerámicas se extiende a un área prácticamente comarcal, hallándose piezas de este grupo en Écija, Osuna, etc ${ }^{13}$.

Si bien las piezas recuperadas en nuestra excavación no se han encontrado in situ, al menos, y ahí radica su importancia, aparecen en un contexto arqueológico cerrado. No parece que formaran parte de las tumbas que se encuentran en este lugar ya que la anchura de ellas era muy superior a la de estas piezas. Por otro lado, los pocos vestigios de cubiertas que han permanecido siempre son de lajas de piedra de cierto grosor. Por último, dos fragmentos de plafones fueron recuperados en la habitación lateral al ábside en el interior de estratos de derrumbe ya que junto a ellos se encontraron restos de placas parietales, materiales constructivos, etc. y nada indica que aquellos niveles se hallaran alterados desde antiguo por remociones posteriores. En este sentido, nos inclinamos por considerarlos como decoraciones arquitectónicas parietales o que funcionaran como ladrillos de tablas para las techumbres cuando estos dispongan en los laterales dos anchas lengüetas sin decorar que posibilitaría su correcta fijación en los alfarjes ${ }^{14}$. En este sentido, ya anteriormente apuntábamos que los techos, a excepción del ábside, podrían configurarse como una estructura de madera cubierta con tejas.

En cuanto a los motivos decorativos contenidos en la placa destaca en primer lugar la inscripción $S A L V O$ EPISC(O)PO MARCIANO. Salvo F. Fita que considera que debe corresponder a un obispo de Sevilla (Fita 1908: 353)que vivió en los últimos años del siglo IV y en los primeros del V, todos los autores desde el estudio de I. de Torres coinciden en señalar que debió tratarse de un obispo astigitano llamado Marciano que vivió en los últimos años del siglo VI y primeros del VII, lo cual está más acorde con las representaciones ornamentales allí reproducidas (Torres 1914).

De este obispo sabemos que fue depuesto de su sede entre los años 622 y 624 con acusaciones tan graves como la de haber hablado en contra del rey, de habitar con una esclava llamada Ustania, de mantener relaciones ilícitas con una dama llamada Bonella y de haber consultado a una adivina llamada Simplicia, acerca de la vida del rey y de su propio futuro. Detrás de todas estas acusaciones estaba un tal Aventius que no sólo consiguió la deposición de Marciano sino que en su lugar fue nombrado él mismo obispo de Écija. Tras su deposición y ante la falta de concilios generales Marciano tuvo que esperar casi diez años para que su caso se viera en el IV Concilio de Toledo que le restituyó el título de episcopus pero no lo situó de nuevo en su sede. Hasta cinco años después no se reúne de nuevo un concilio general. El VI Concilio (638), en su primera sesión trató el caso de lleno y desenmarañó el complot. Interrogaron a diecisiete testigos (cinco de ellos godos) con el máximo rigor. Así en el asunto de Simplicia, se comprobó que Aventius había empleado como testigo a una persona llamada Recesvinto quién había prestado su testimonio teniendo menos de catorce años, lo cual era ilegal. Sin el testimonio de Recesvinto, la acusación se basaba en un único testigo, un tal Dormitio, y, según el código de Alarico, el testimonio de un único testigo era inadmisible. Aventius había convencido a dos mujeres analfabetas, Franca y Honorata, para que firmasen una declaración de evidencia que ellas mismas no podían leer y que para colmo era contraria a lo que ellas sabían. Por último,

13. Varias placas procedentes de estas localidades se encuentran expuestas en la Sala dedicada al período Alto Medieval -visigodo y musulmán- del Museo Arqueológico Provincial de Sevilla.

14. Esta segunda hipótesis debe tomarse con ciertas reservas ya que el peso que estos materiales podría comprometer la estabilidad de la edificación. En nuestro caso este problema se vería aliviado, aunque no resuelto, por haber sido edificada en sillares. 
se verificó que en realidad su ayuda de cámara no era una esclava sino su hermano, llamado Belisarius. Ante la rotundidad de estos hechos se le restituyó a su sede astigitana pero no parece que viviese mucho tiempo después de esto ya que en el 646 encontramos otro obispo en su sede (Thompson 1990: 327-328).

Dejando a un lado muchas de las circunstancias "extraordinarias" que rodearon el caso, una lectura ajustada de las acusaciones dentro del contexto político del momento permite inferir que detrás de todo se hallaba algo más que una cuestión estricta de orden religioso. En efecto, la política de refuerzo del poder imperial llevada a cabo por Suintila había provocado un extendido descontento entre la nobleza que no estaba dispuesta a ver impasible como se amenazaba sus más importantes privilegios. A este respecto cabe destacar que dos de las acusaciones falsas (?) por la que fue depuesto el obispo Marciano en el sínodo provincial del 628-629 fueron haber hablado en contra del rey y haber consultado a adivinos sobre la muerte del mismo por lo que estaría preso un año, justo hasta el derrocamiento de Suintila.

El tema de venera sostenida sobre columnas y con el crismón triunfante en el fondo se halla bastante extendido en hornacinas y nichos de piedra, tanto en los talleres de Mérida donde son fechados en los siglos VI-VII, como en los de Toledo cuyas piezas se adscriben al siglo VII (Palol 1968: Láms. 20, 30, 31 y 56). También un esquema compositivo idéntico al nuestro se aprecia en la serie de ladrillos de "Bracarius".

En cuanto a la representación vemos que a diferencia de las esculturas en piedra nuestras piezas carecen del característico dintel que cierra por abajo el arco. Este está trazado con una estrecha línea que descansa en el centro de los capiteles. También los gallones de la venera confluyen en el centro sin abrir, como en los nichos, esos gruesos semicírculos. En las enjutas se disponen sendos delfines muy frecuentes en las representaciones cristianas que son una clara copia de temas musivarios paganos que pasan al repertorio cristiano también en temas musivos. No obstante, el diseño estilizado y fino de estos animales los emparejan más a los modelos procedentes de la orfebrería. Las representaciones de peces hay que relacionarlas con el sacramento del bautismo, con el simbolismo de Cristo-Pez, que presente en el agua bautismal, tiene la virtud de engendrar nuevos cristianos, los pisciculí (Martín 1982: 42).

Los edículos y los arcos son signos arquitectónicos cuyos significados serían los mismos que en época romana de donde parecen proceder, a saber: destacar la preeminencia de los temas que en su interior se recogen. Estos no son otros que la imagen de grandes crismones con el alfa y la omega que deben interpretarse como símbolos de lucha y triunfo por parte de la fe católica contra la herejía arriana. El alfa y omega manifiestan la divinidad del Hijo como principio generador y fin último de la Vida. Tampoco se debe olvidar que estas letras tenían dentro del pensamiento patrístico una lectura trinitaria, dado que ambas necesitan escribirse mediante tres trazos unidos e independientes ${ }^{15}$. El alfa y omega fueron empleados como signos contra el arrianismo y su expansión debe vincularse al éxito del catolicismo.

Por último, indicar que esta composición es típicamente oriental, localizándose ampliamente en el arte bizantino, siendo el momento de mayor auge el siglo VI y la ciudad de Constantinopla y su radio inmediato de influencia. Es posible que de allí llegara a los talleres más importantes hispánicos como Mérida o Toledo y desde aquellos focos receptores se extendiese a los centros locales.

Está claro que, a tenor de la cronología que puede asignarse a las representaciones ornamentales que contienen los ladrillos, sus paralelos con los aparecidos en nichos y hornacinas en piedra, la referencia al obispo astigitano, etc., hacen evidente que estos materiales debieron fabricarse en el último tercio del siglo VI o principios del VII. En este sentido, el mensaje "antiarriano" de la ornamentación de los ladrillos de la serie Marciano y, principalmente, Bracarius que tuvo una mayor difusión por el ámbito suroccidental estaría en consonancia cronológica con el Concilio III de Toledo. Ello nos develaría el interés de la nueva religión estatal por borrar cualquier manifestación de la antigua.

15. Aprim. In Apoc. I,8: Beat. In Apoc. I,3. Cita extraída de Barroso y Morín (1996: 56-57). 


\section{CONCLUSIONES.}

Dos cuestiones generales nos interesa destacar aquí: La primera hace referencia al momento de construcción de la basílica. Hemos insistido en distintas páginas de este trabajo sobre las precauciones que impone cualquier propuesta cronológica que pretenda establecerse a partir de argumentos estrictamente comparativos. No obstante, el análisis de los restos arqueológicos recuperados en la excavación de la iglesia y expuestos en los apartados anteriores pensamos que ofrece una visión suficientemente contrastada sobre cuestiones tan diversas como, por ejemplo, las técnicas y características edilicias, los repertorios formales y morfológicos decorativos, los elementos funcionales del edificio, los temas epigráficos, etc. que nos permite adscribir, con cierta precisión, la construcción de la iglesia a finales del siglo VI o inicios del VII.

Los restos arqueológicos de esta etapa descubiertos en el castillo se reducen, por el momento, a una serie de hallazgos aislados que confirman la existencia de un modesto asentamiento espacialmente reducido a los límites de la actual bancada noroeste de la cerro. Se trata de un poblamiento muy limitado al que la construcción de una basílica de estas características le resultaría un esfuerzo económico considerable que sobrepasaría con mucho su capacidad. Tenemos, por tanto, que ver aquí una fundación promovida desde los estamentos superiores -civiles o eclesiásticos ${ }^{16}$ - dirigida, no sólo a la población del castillo, sino a todas las comunidades rurales dispersas de esta zona como parecen verificar, además, su situación y sus proporciones ${ }^{17}$.

Ahora bien, la erección de la iglesia no puede considerarse como un hecho aislado sino que debe inscribirse para su correcta comprensión en un fenómeno más generalizado que afectó a toda la comarca. En efecto, a mediados del siglo VI asistimos a lo que podemos denominar una cristianización del paisaje rural cuyos testimonios principales serían entre otros la basílica de Morón, la iglesia de El Casar ${ }^{18}$, Zahara (Salvador 1990: 310), Bornos ${ }^{19}$ y el cenobio masculino que se alzaba en el término histórico de Morón como atestigua la inscripción funeraria de Fulgentius del año 543 descubierta a escasos kilómetros de la ciudad y en la que aparece como monachus (Vives 1942: n. 1. 150).

Por supuesto, a este fenómeno no sería ajeno a las situaciones políticas que atravesó la zona meridional en aquellas fechas: Las campañas de Leovigildo, Recadero y sus sucesores lograron alejar a los imperiales de la campiña ${ }^{20}$. Tras la rebelión de Hermenegildo se abre un período de relativa paz interior. Los esfuerzos "autonomista" de la nobleza meridional concluye tras las conversión de Recadero produciéndose la alianza definitiva entre la monarquía, la aristocracia goda y la hispanorromana.

Estas propicias circunstancias animaron a la aristocracia a realizar este esfuerzo evangelizador conscientes de los beneficios económicos que las fundaciones les reportarían ${ }^{21}$. En este sentido, resulta curioso comprobar

16. El considerarla como una posible fundación eclesiástica es una hipótesis que nos sugiere la presencia de los ladrillos decorados con la firma de Marciano, episcopus astigitano y, por tanto, máxima autoridad de la diócesis a la que pertenecería nuestra iglesia en el momento de su construcción. En este sentido, es interesante comprobar que la dispersión que muestran los plafones de la serie Marciano no superan, por el momento, el ámbito territorial de la primitiva circunscripción de Écija.

17. Sólo nos ha quedado la mitad de la cabecera pero a tenor de estas medidas y en comparación con las proporciones métricas de basílicas como Son Peretó, Son Bou, Es Fornás, Gerena, etc. podemos deducir para nuestra iglesia unas dimensiones para la cabecera y las naves en torno a los $12,80 \mathrm{~ms}$. de ancho por $25,61 \mathrm{~ms}$. de largo.

18. Fue construida en el siglo VII por el obispo Pimenivs como consta en la inscripción alusiva a su fundación. (Ruiz 1985: 216-217).

19. Es interesante comprobar cómo las inscripciones fundacionales de las iglesias de El Casar, Zahara e incluso la de Bornos, por citar otra muy próxima a nuestro territorio y adscribible a estas fechas, parecen referirse a la deposición de reliquias en el momento de la consagración.

20. Leovigildo conquista Asidonia el año 571. También debió tomar Sagontia puesto que para llegar a Medina-Sidonia tenía que pasar por allí. Pero no será definitivamente ocupada hasta el reinado de Witerico. Basti, por último también parece conquistada por Leovigildo pues en las actas del concilio III de Toledo están suscrita por un episcopus bastetanus

21. "No obstante, estos fines espirituales...quedarán sumamente enmascarados por unos fines de apropiación de oblaciones por parte de los mismos constructores de los fieles que reciben la cura espiritual en su distrito, de modo que cobrarán una especie de cuota por acercar los beneficios espirituales desde las ciudades o parroquias rurales más lejanas. A su vez estas oblaciones 
que la más antigua de estas edificaciones religiosas sea precisamente un monasterio, ya que éste fue el subterfugio a que recurrieron los fundadores de "iglesias propias" para substraerlas al régimen general de la diócesis; esto es, las hacían consagrar sub specie monasterii (Orlandis 1991: 474-475) aunque en él no viviese comunidad religiosa, ni existiese una regla aprobada por el obispo ${ }^{22}$. Ahora bien, no sabemos si detrás de algunos de estos actos sólo hay que ver la intención de adquirir nuevos derechos sobre las poblaciones rurales de la zona o si fueron acompañados, dada la ubicación de algunas de estas iglesias, de puesta en explotación de nuevos áreas. No debemos olvidar que San Isidoro y el movimiento fructuosiano proponen para sus monasterios lugares ásperos y solitarios y a tales mandatos se deben las construcciones de monasterios en la serranía de Córdoba, en Rus (Jaén), etc. Sea como fuese, estas edificaciones suponen un paso más en la consolidación en nuestra área de las relaciones protofeudales que en aquellos años se estaban estableciendo en toda la Península.

La segunda cuestión que nos interesa destacar se refiere al mensaje conminatorio que encierra el programa ornamental de nuestra iglesia. Los escasos repertorios decorativos asociados a ella hacen referencia exclusiva a dos temas muy concretos: la conversión de nuevos cristianos los pisciculi y símbolos contra el credo arriano que, aunque no parece que se hallara muy extendido por la zona meridional de la Península, tampoco debemos olvidar que entre los escasos testimonios epigráficos aparecidos uno alude a un personaje noble godo-Hilduarens- muerta en el 504. Las luchas por someter a la nobleza meridional y por recuperar los territorios imperiales seguramente desplazó a estas tierra de frontera importantes contingentes visigodos. Por lo tanto, no sería extraño que tras el III Concilio de Toledo las nuevas iglesias que se iban levantado en la región incluyeran un programa ornamental contra aquella fe hereje que había sido derrotada por el catolicismo. En este sentido, el éxito de la representación del crismón con el alfa y omega encerrado en una venera y su gran difusión se inscribe dentro de esa atmósfera general de desatado triunfalismo sobre la herejía y de constante amenaza del proselitismo hebreo.

Por último, señalar que la localización de esta basílica junto a la de Gerena empieza a definir con mayor claridad cada vez un grupo de iglesia de cabecera recta tripartita en el sudoeste peninsular estrechamente emparentado, tanto desde el punto de vista formal como técnico, con el grupo balear.

\footnotetext{
también podrán ser objeto de apropiaciones por parte de los obispos, que no se conformarán con la tercera parte que canónicamente les corresponde. De este modo el verdadero fin sirve de pantalla para cubrir en apariencia una motivación económica, pero que al fin supone una cuota de seguridad." (Cerrillo 1978: 23-24)

22. Aunque hay un interés abierto por parte de la iglesia por controlar o beneficiarse de estas fundaciones como demuestran las extensas relaciones de cánones que se promulgaron al respecto, lo ciertos es que los fundadores laicos - ¿potentiores?-supieron salvaguardar los beneficios económicos que les aportaban estas iglesias frente a las apetencias de los obispos. Incluso la legislación eclesiástica apoyó un dominio cada vez más efectivo de los fundadores como se aprecia en los cánones 1 y 2 del Concilio IX de Toledo (655)
} 


\section{BIBLIOGRAFÍA.}

BARROSO, R. y MORÍN, J. (1996): "Ensayo sobre el origen, funcionalidad e iconografía de los nichos y placas-nichos de época visigoda en la Península Ibérica", Boletín de Arqueología Medieval 10: 9-87.

BENDALA, M. (1976): La necrópolis romana de Carmona (Sevilla). Sevilla.

BLAZQUEZ, J.M. (1975): Diccionario de las religiones prerromanas de Hispania. Madrid.

BOHORQUES, A. (1994): Anales de Morón. Transcp. (1633-1642), introd., notas e índices de J. Pascual Barea. Cádiz.

BORRAS I FELIU, A. (1982): “El culte a les pedres i a les columnas. El Pilar de Saragossa”. II Reunió d'Arqueología Paleocristiana Hispánica: 281-295.

CERRILLO, E. (1978): Las construcciones basílicales de época paleocristiana y visigoda en la antigua Lusitania. Salamanca.

COLLANTES DE TERÁN Y CAAMAÑO, F. (1990): Historia de Morón de la Frontera. Reed. por M. García y A. M. Bernal. Morón de la Frontera.

CORZO, R. (1989): "Visigótico y prerrománico". Historia del arte, 16. Madrid.

CRUZ VILLALÓN, M. (1985): Mérida visigoda. La escultura arquitectónica y litúrgica. Badajoz.

DALMAIS, I.H. (1967): La continuité des cultes. Paris.

FERNÁNDEZ, F. et alii. (1986): "La basílica de época paleocristiana-visigoda de Gerena (Sevilla)". I Congreso de Arqueología Medieval Española II: 41-50.

_ (1987): "La basílica y necrópolis paleocristiana de Gerena (Sevilla)”. Noticiario Arqueológico Hispánico 29: 103-199.

FITA, F. (1908): "Inscripciones romanas y visigóticas de Tarifa, Ronda y Morón de la Frontera". Boletín de la Real Academia de la Historia LIII: 344-353.

GARCÍA LÓPEZ, J.J. (1982): Crónicas para una historia de Morón. Morón de la Frontera.

GODOY FERNÁNDEZ, C. (1990): "A propósito de las iglesias y mosaicos de Madaba. Problemas sobre la funcionalidad litúrgica de los edificios de culto". Espacio, Tiempo y Forma: 3: 335-387. (1995): Arqueología y liturgia. Iglesias hispánicas (siglos IV al VIII). Barcelona.

GONZÁLEZ, F.A.: Colección de Cánones de la iglesia española. Madrid.

GONZÁLEZ FERNÁNDEZ, J. (1996): Corpus de Inscripciones Latinas en la Provincia de Sevilla. Vol II. Tomo IV. Sevilla.

HILLGARTH, J.N. (1980): "Popular religion in visigothic Spain”. Visigothic Spain: New approaches: 3-60.

KRAUTHEIMAR, R. (1984): Arquitectura paleocristiana y bizantina. Madrid.

LAURENTIN, R. (1967): "Foi et mythe en theólogie mariale". Revue de Théologie 89.

MARCOS POUS, A. (1961): "Dos tumbas emeritenses de incineración”. Archivo Español de Arqueología XXXIV: 90 y ss.

MARTÍN GÓMEZ, C. (1982): "Placas decoradas de época paleocristiana y visigoda, con inscripción, del Museo Arqueológico de Sevilla". Museos 1: 37-43.

NAVARRO, R. y MAURI, A. (1994): "Santa Margarida de Martorrell: la transició de l'antiguitat tardana al món medieval". IV Congreso de Arqueología Medieval Española II: 341-344.

OLMO, L. (1988): “Arquitectura religiosa y organización litúrgica en época visigoda. La basílica de Recópolis". Archivo Español de Arqueología 61: 157-178.

ORLANDIS, J. (1991). "El cristianismo y la iglesia en la España Visigoda". Historia de España Menéndez Pidal III,1: 474-475.

PALOL, P. de (1967): Arqueología cristiana de la España romana. Siglos IV-VI. Valladolid.

- (1968): Arte Hispánico de la época visigoda. Barcelona. 
(1982): "La basílica de es Cap des Port, de Fornells, Menorca". II Reunió d'Arqueología Paleocristiana Hispánica: 353-404.

(1989): "La arqueología cristiana en la Hispania romana y visigoda. Descubrimientos recientes y nuevos puntos de vista". XI Congreso Internacional de Arqueología cristiana: 1975-2022. (1991): “Arte y arqueología”. Historia de España Menéndez Pidal III, 2: 271-428. (1994): “L’Arqueología cristiana hispánica despres de 1982”. III Reunió d'Arqueología Paleocristiana Hispánica: $3-40$

PUERTAS, R. (1975): Iglesias hispánicas (siglos IV al VIII). Testimonios literarios. Madrid.

RUIZ, M.Ma. (1985): Carta arqueológica de la campiña sevillana. Zona Sureste. Sevilla.

SALVADOR VENTURA, F. (1990): Hispania meridional entre Roma y el Islam. Economía y sociedad. Universidad de Granada.

SCHLUNK, H. (1947): “Arte visigodo". Ars Hispaniae, II. Madrid.

-(1971): "La iglesia de S. Giao, cerca de Nazaré. Contribución al estudio de la influencia de la liturgia en la arquitectura de las iglesias prerrománicas de la Península Ibérica". II Congreso Nacional de Arqueología: 503-523.

THOMPSON, E.A. (1990): Los godos en España. Madrid.

TORRES Y LEÓN, I. de (1914): "Los ladrillos visigóticos de Val-Duan". Revista de Archivo Biblioteca y Museos XXVIII: 265-290.

VIVES, J. (1942): Inscripciones cristiana de la España romana y visigoda. Barcelona. (1963): Concilios visigóticos e hispanorromanos. Barcelona-Madrid. 


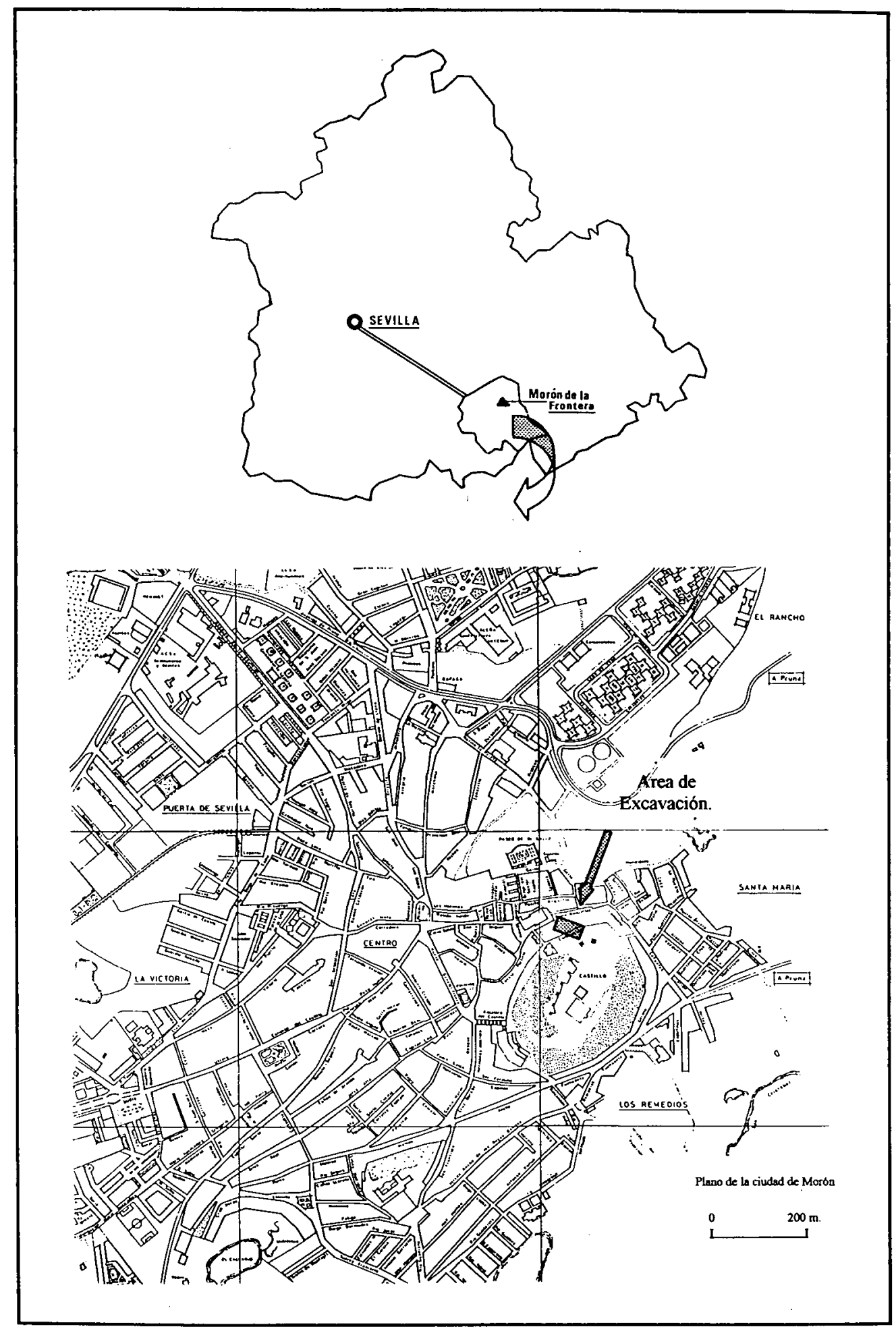

Fig. 1.- Plano de la provincia de Sevilla y del sector suroriental de la ciudad de Morón con indicación del área de excavación. 


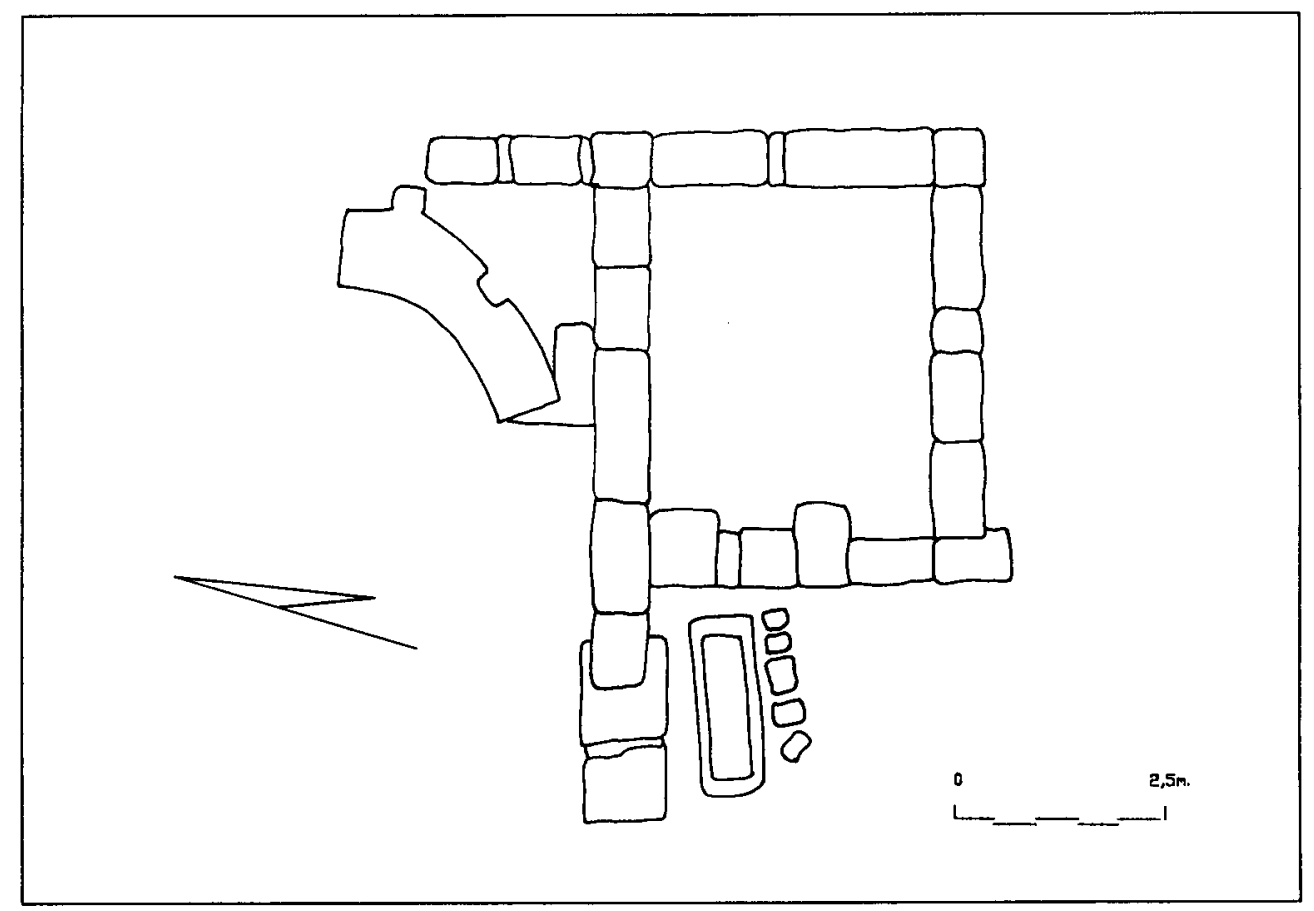

Fig. 2.- Planta de la basílica visigoda.

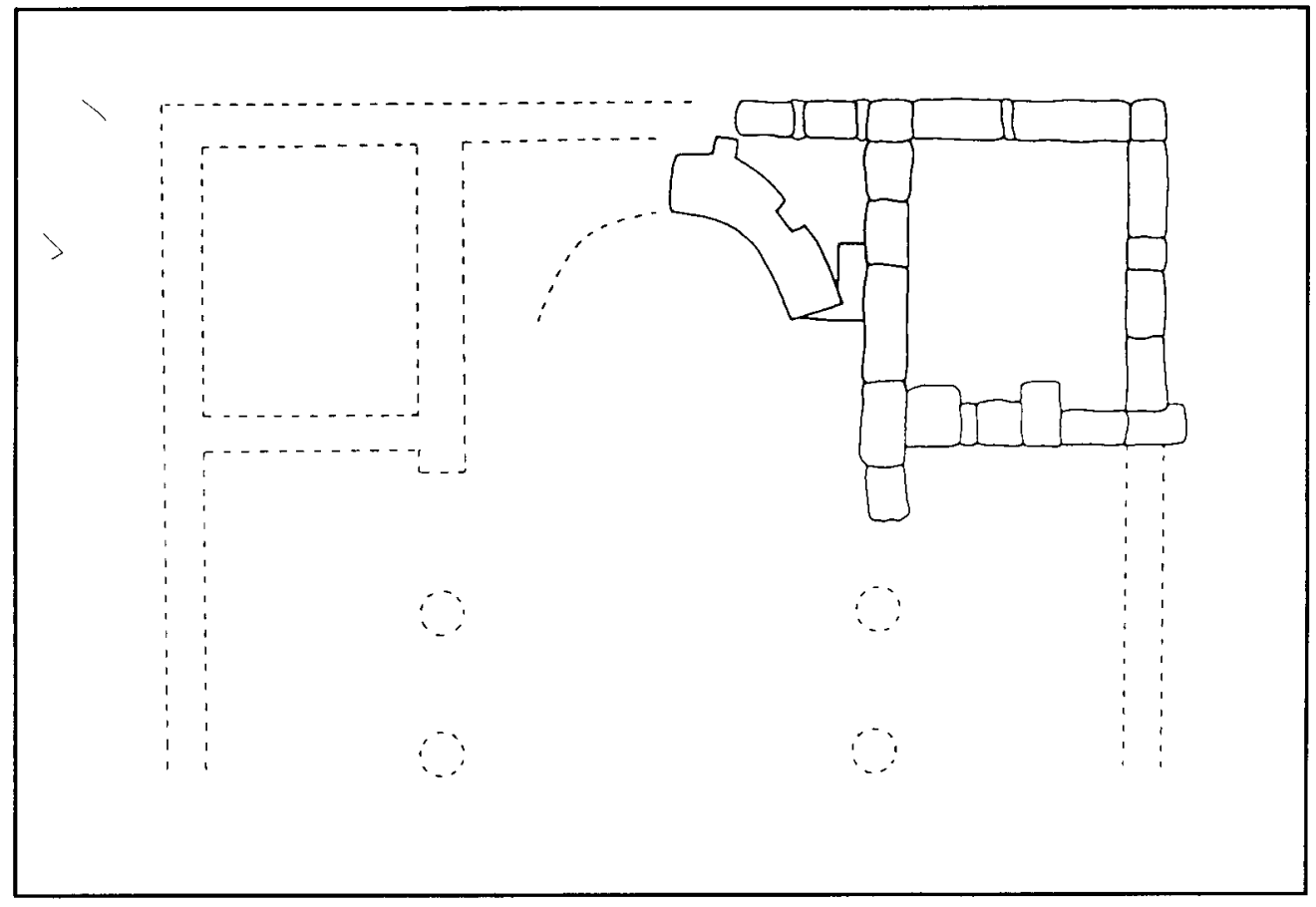

Fig. 3.- Restitución hipotética de la planta de la iglesia. 


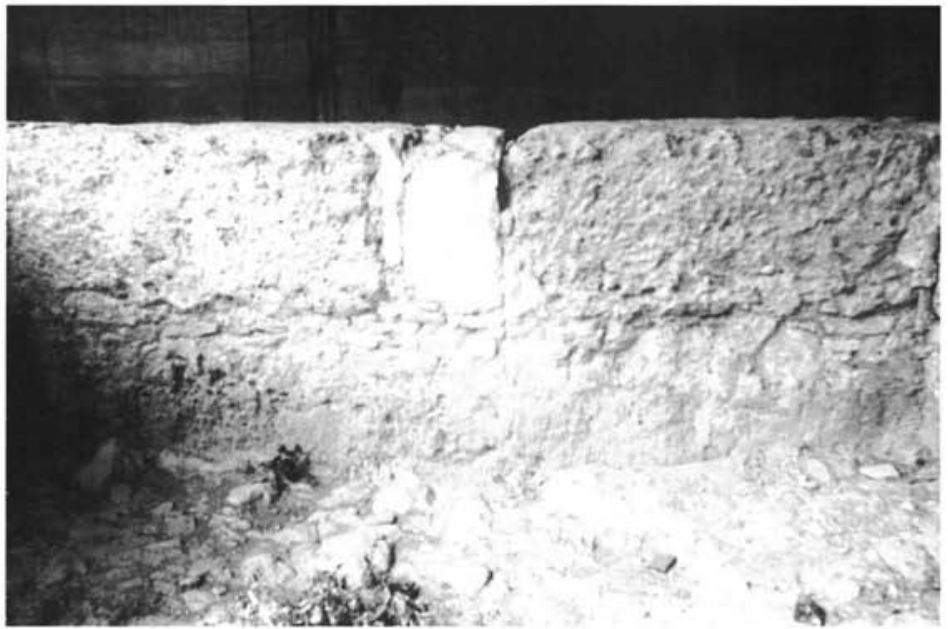

Lám. 1.- Detalle constructivo de los paramentos de la iglesia (Foto E.T.C.)

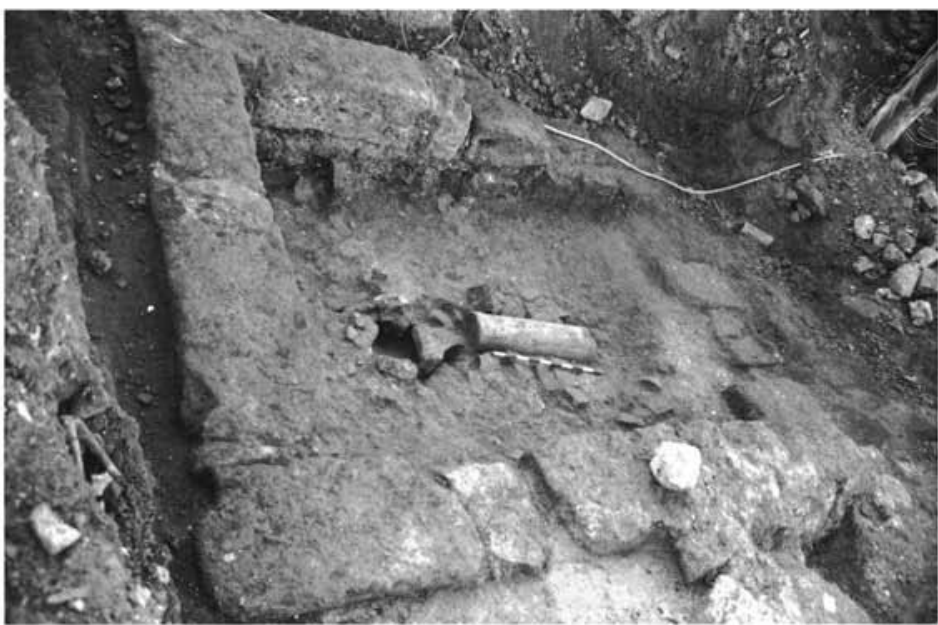

Lám. 2.- Vista de la sala meridional de la cabecera de la iglesia durante las obras de acondicionamiento de las laderas del cerro (Foto E.T.C.). 


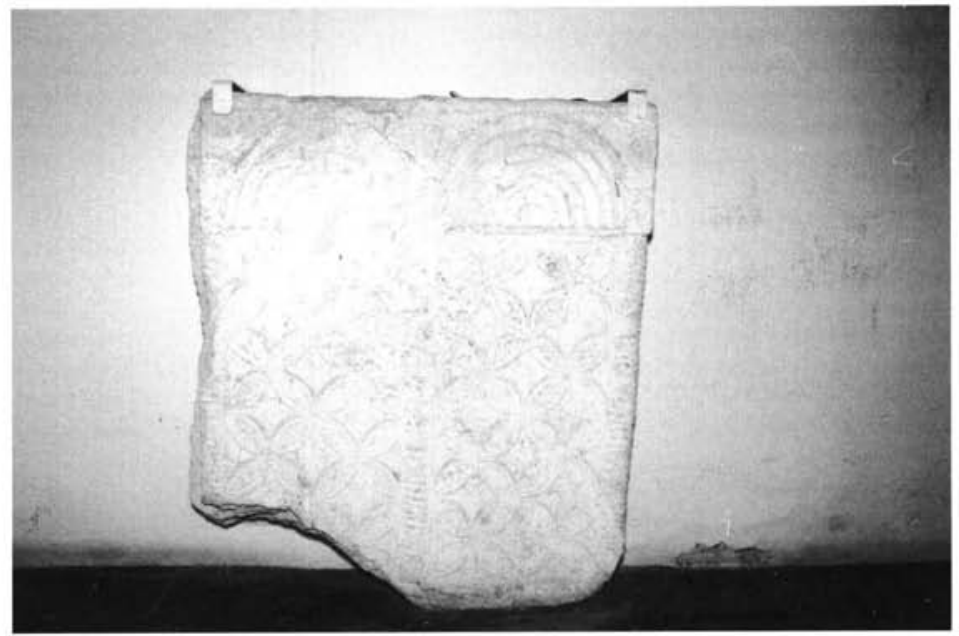

Lám. 3.- Cancel (Foto E.T.C.)

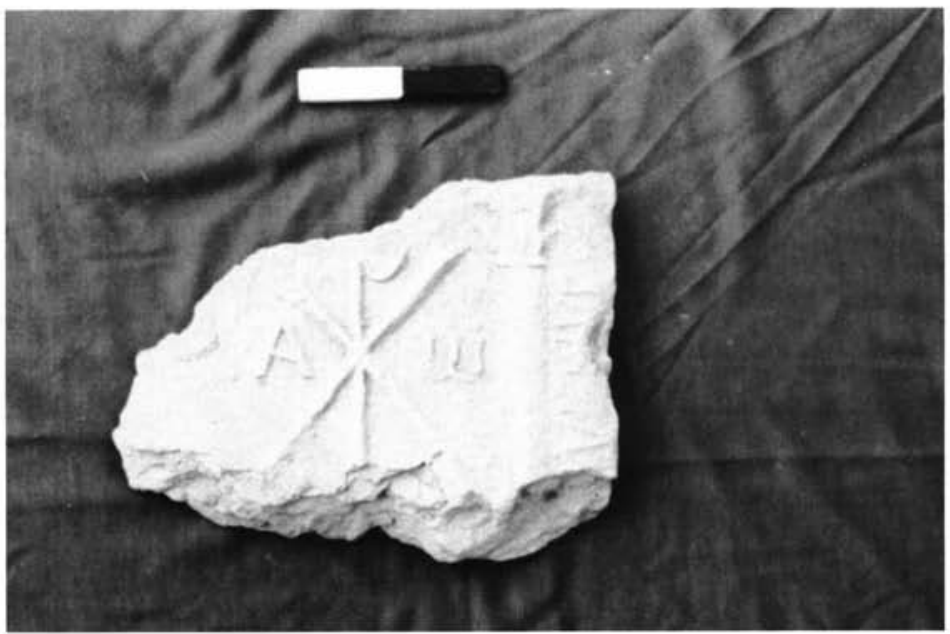

Lám. 4.- Ladrillo de la serie "Marciano" aparecido durante las obras de los años sesenta (foto F.F.V.). 


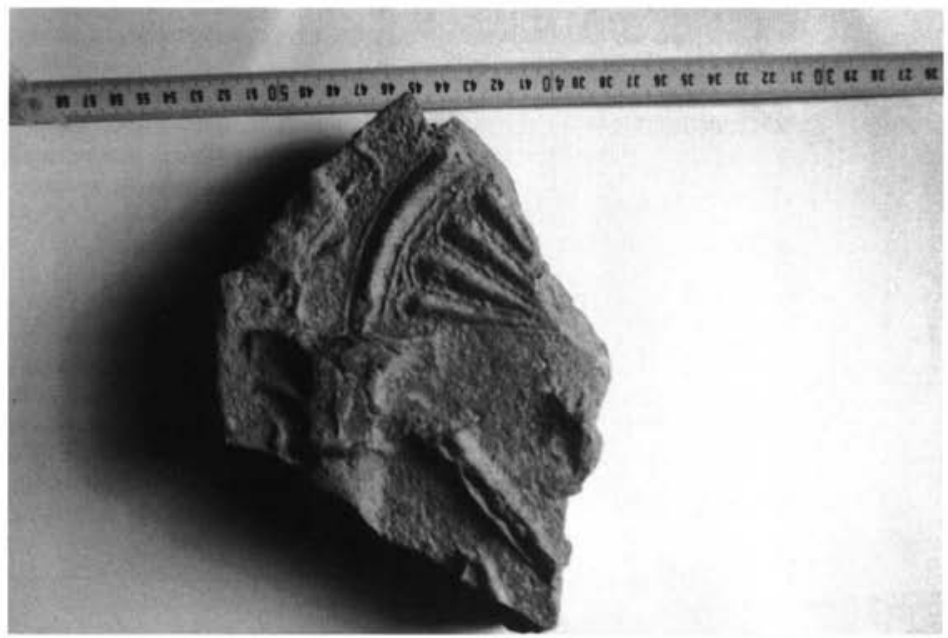

Lám. 5.- Ladrillo de la serie "Marciano" aparecido en la excavación.

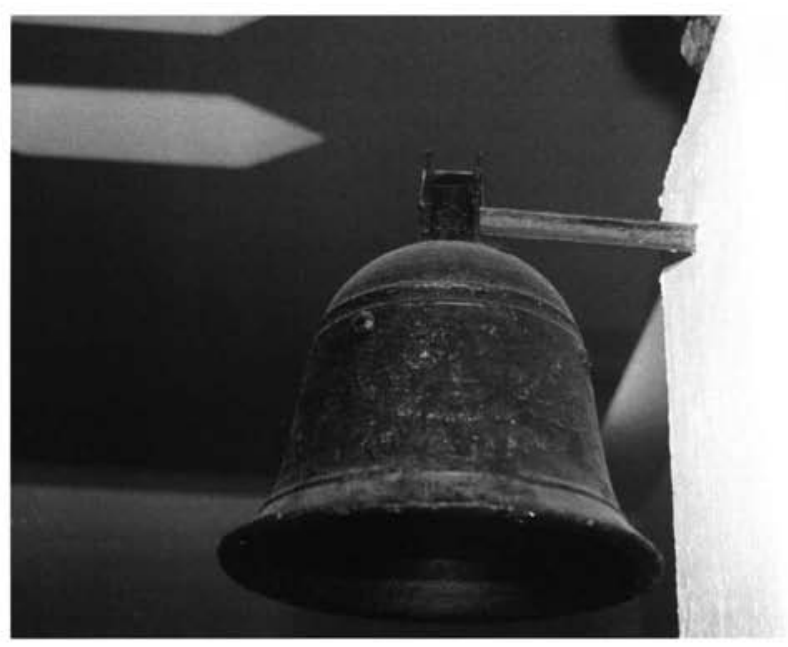

Lám. 6.- Campana visigoda depositada en el Museo Arqueológico Provincial de Sevilla. 